\title{
The MIF - I73G/C polymorphism and risk of coal workers' pneumoconiosis in a Chinese population
}

This article was published in the following Dove Press journal:

International Journal of Interferon, Cytokine and Mediator Research

12 May 2012

Number of times this article has been viewed

Kexin Jin ${ }^{1, *}$

Xiaoming $\mathrm{Ji}^{1, *}$

Shasha Wang'

Zhifang Song ${ }^{2}$

Xiaomin $\mathrm{Jia}^{2}$

Zhiguo Hou'

Ting Wang'

Meilin Wang'

Chunhui $\mathrm{Ni}^{\prime}$

'Department of Occupational

Medicine and Environmental Health,

School of Public Health, Nanjing

Medical University, Nanjing, ${ }^{2}$ Genera Hospital of Xuzhou Mining Business

Group Co, Ltd, Xuzhou, People's

Republic of China

*These authors contributed equally to this work

Correspondence: Chunhui $\mathrm{Ni}$ and Meilin Wang

Department of Occupational Medicine and Environmental Health, School of

Public Health, Nanjing Medical University, I 40 Hanzhong Road, Nanjing 2 10029,

People's Republic of China

Tel +862586862748

$\mathrm{Fax}+862586527613$

Email chni@njmu.edu.cn
Objective: To investigate the possible relationship between macrophage migration inhibitory factor $(M I F)-173$ polymorphism (rs755622) and susceptibility to coal workers' pneumoconiosis (CWP) in a Chinese population.

Methods: A total of 699 patients with CWP and 677 controls were genotyped for the polymorphism by TaqMan method.

Results: Our results showed that the $M I F-173 \mathrm{CC}$ genotype was associated with a significantly decreased risk of CWP (adjusted odds ratio $=0.44,95 \%$ confidence interval $=0.22-0.85$ ), compared with the GG/GC genotype, particularly among smokers.

Conclusion: Our results indicate that the functional $M I F-173 \mathrm{G} / \mathrm{C}$ polymorphism is involved in the etiology of CWP and susceptibility to this disease. Further studies are warranted to validate our findings.

Keywords: $M I F$, polymorphism, coal workers' pneumoconiosis, molecular epidemiology

\section{Introduction}

Macrophage migration inhibitory factor $(M I F)$ is a key proinflammatory cytokine and chemokine-like function cytokine that is rapidly released from various immune cells, endothelial cells, tissue macrophages, and certain parenchymal cells upon inflammatory and stress stimulation. ${ }^{1}$ It has been generally acknowledged that MIF plays a pivotal role in the pathogenesis of acute and chronic inflammatory diseases such as septic shock, rheumatoid arthritis, inflammatory lung disease, and atherosclerosis by promoting and amplifying involved inflammatory reactions such as monocyte/ macrophage survival, MAPK signaling, or inflammatory cytokine release. ${ }^{1-4}$ More and more evidence shows that $M I F$ also plays an essential and crucial role in cell proliferation and cell cycles, ${ }^{5,6}$ which together with $M I F$ properties of cytokine and chemokine are implicated in fibrotic diseases and cancers, such as cystic fibrosis, ${ }^{7}$ liver fibrosis,${ }^{4}$ idiopathic pulmonary fibrosis, ${ }^{8}$ and pancreatic cancer. ${ }^{9}$

Coalworkers' pneumoconiosis (CWP) is one of the most widespread occupational lung diseases in China. It is a kind of lung fibrosis without effective treatment, produced by prolonged and extensive exposure to coal and silica dust, which is characterized by lung chronic inflammation and fibrotic nodular lesions that usually lead to progressive fibrosis. Ingestion of coal dust or silica by alveolar macrophages leads to cell death and release of intracellular dust, which is then taken up by other macrophages. This recurring cycle of macrophage phagocytosis and cell death perpetuates the inflammatory process. ${ }^{10}$ During this inflammatory process, macrophages become activated and release inflammatory mediators, such as chemokines and cytokines, which attract 
neutrophilic granulocytes, upregulate alvolitis, damage the alveolar epithelial cells, and induce the formation of gaps in the epithelial basement membranes. The migration of fibroblasts through these gaps into the alveolar space leads to intra-alveolar fibrosis. ${ }^{11,12}$

The extent of fibrosis varies greatly among individuals who have been exposed to similar levels of mineral dust, indicating a prominent role for host genetic factors that influence the fibrogenic tissue response. ${ }^{13,14}$ Therefore, understanding genetic polymorphism and the interaction between genetic variation and dust exposure may aid in the identification of high-risk individuals and prevent them from developing CWP. Recent studies have reported that MIF is capable of regulating the expression of cytokines such as tumor necrosis factor- $\alpha$, interleukin (IL)-1 $\beta$, IL-6, and IL-8, some of which play a critical role in the pathogenesis of CWP. ${ }^{15}$ MIF can also induce macrophage production of cytokines and promote T-lymphocyte proliferation. ${ }^{1}$ In lung tissues, $M I F$ is expressed in alveolar macrophages, alveolar endothelium, and bronchial epithelial cells. ${ }^{16}$ The $M I F-173 \mathrm{G} / \mathrm{C}$ (rs755622) polymorphism located in the 5 'flanking region of the MIF gene has been shown to be functionally relevant in vitro and in vivo. ${ }^{17-19}$

Although research has focused on the association between the MIF polymorphisms and the susceptibility to diseases, ${ }^{20-22}$ to date no data exist on their roles in CWP. Therefore, the purpose of the present research was to investigate the association between the $M I F-173 \mathrm{G} / \mathrm{C}$ polymorphism and the risk of CWP in a Chinese population.

\section{Materials and methods Study subjects}

This study, including 699 CWP patients and 677 controls, has been described previously. ${ }^{23}$ All subjects were recruited in an ongoing study from five coal mines of Xuzhou Mining Business Group Co, Ltd, People's Republic of China, between January 2006 and December 2010. A high kilovolt chest X-ray and physical examinations were performed to reconfirm the diagnoses based on the China National Diagnostic Criteria for Pneumoconiosis (GBZ70-2002), which is the same as the 1980 International Labor Organization classification of pneumoconiosis in the judgment of opacity profusion. ${ }^{24}$ The CWP patients were classified into stage I, stage II, or stage III according to the size, profusion, and distribution range of opacities on chest X-ray. The controls were selected from the same coal mines and were matched for age (within 5 years), dust exposure period, and job type. Subjects were excluded if they had clinical evidence of autoimmunity diseases or had immunosuppressive or immunostimulating therapy or radiotherapy. To obtain individual information including age, dust exposure period, job types, smoking status, and others, an epidemiological survey was done by face-to-face interviewers in order. The questionnaire was blinded regarding the case or control status of participants. A blood sample of $5 \mathrm{~mL}$ was obtained from all subjects and used for routine lab tests. The written informed consent was obtained from all subjects and the research protocol was specifically approved by the Institutional Review Board of Nanjing Medical University.

\section{Genotyping}

Genomic DNA was isolated from peripheral blood lymphocytes using the conventional phenol-chloroform method. The $M I F-173 \mathrm{G} / \mathrm{C}$ polymorphism was genotyped using the TaqMan method with the ABI 7900HT real-time polymerase chain reaction system according to the manufacturer's instructions (Applied Biosystem, Foster City, CA). The sequences of primer and probe for each single nucleotide polymorphism are available on request. More than $10 \%$ of the samples were randomly selected for repeated genotyping for confirmation, and the results were $100 \%$ concordant. Genotyping was conducted by two researchers independently in a blinded fashion.

\section{Statistical analyses}

Differences in the distributions of demographic characteristics, selected variables, and frequencies of genotypes of $M I F-173 \mathrm{G} / \mathrm{C}$ polymorphism between the CWP cases and controls were evaluated by using the Student's $t$-test or $\chi^{2}$ test. Hardy-Weinberg equilibrium was tested using a goodness-of-fit $\chi^{2}$ test. The associations between genotypes and CWP were estimated by computing odds ratios (ORs) and their $95 \%$ confidence intervals (CIs) from unconditional logistic regression analysis with the adjustment for possible confounders. The statistical power was calculated using the PS software (http://biostat.mc.vanderbilt.edu/twiki/ $\mathrm{bin} /$ view/Main/PowerSampleSize). We have $80 \%$ power at 0.05 significance level to detect an OR of 1.43 or higher and 0.67 or lower with an exposure frequency of $20 \%$ under the current sample size. In this study, the dust exposure cutoff used for the stratified analysis accorded with the median of dust exposure years of the recruited patients and controls. All statistical tests were two-sided at a significance level of 0.05 and were analyzed using SAS software (version 9.1; SAS Institute, Inc, Cary, NC). 


\section{Results}

\section{Characteristics of the study population}

The frequency distributions of the selected characteristics of the cases and controls are presented in Table 1. There was no significant difference in the distribution of age ( $P=0.091)$, exposure years $(P=0.085)$, and work types $(P=0.404)$ between the cases and the controls. The smoking status of CWP was similar to the controls $(P=0.356)$, but the pack-years smoked in CWP cases were significantly less than those of controls $(P<0.001)$. The frequency distributions and means of the selected characteristics were matched adequately between cases and controls. In addition, of the 699 CWP cases, $421(60.2 \%)$ were stage I, 214 (30.6\%) were stage II, and the remaining 64 (9.2\%) were stage III.

\section{Genotype distributions of MIF polymorphism among the cases and controls}

The observed MIF -173G/C genotypes among the control subjects conform to the Hardy-Weinberg equilibrium $\left(\chi^{2}=0.046, P=0.229\right)$. The genotypes and allele frequencies of the $M I F-173 \mathrm{G} / \mathrm{C}$ polymorphism and their associations with risk of CWP are shown in Table 2. The MIF genotype

Table I Demographic and selected variables among the coal workers' pneumoconiosis (CWP) cases and control subjects

\begin{tabular}{|c|c|c|c|c|c|}
\hline \multirow[t]{2}{*}{ Variables } & \multicolumn{2}{|l|}{$\begin{array}{l}\text { CWP } \\
(n=699)\end{array}$} & \multicolumn{2}{|l|}{$\begin{array}{l}\text { Controls } \\
(n=677)\end{array}$} & \multirow[t]{2}{*}{$P$} \\
\hline & $\mathbf{N}$ & $\%$ & $\mathbf{N}$ & $\%$ & \\
\hline Age, year (mean \pm SD) & $67.8 \pm 11.0$ & & $66.9 \pm 8.2$ & & 0.091 \\
\hline $\begin{array}{l}\text { Exposure years } \\
\text { (mean } \pm \text { SD) }\end{array}$ & $26.6 \pm 9.0$ & & $27.4 \pm 8.0$ & & 0.085 \\
\hline Smoking status & & & & & 0.356 \\
\hline Never & 345 & 49.4 & 351 & 51.8 & \\
\hline Ever & 354 & 50.6 & 326 & 48.2 & \\
\hline Former & 158 & 22.6 & 84 & 12.4 & \\
\hline Current & 196 & 28.0 & 242 & 35.8 & \\
\hline Pack-years smoked & & & & & $<0.001$ \\
\hline 0 & 345 & 49.4 & 351 & 51.8 & \\
\hline $0-20$ & 223 & 31.9 & 133 & 19.7 & \\
\hline$>20$ & $13 \mid$ & 18.7 & 193 & 28.5 & \\
\hline Work type & & & & & 0.404 \\
\hline Tunnel and coal mining & 663 & 94.9 & 632 & 93.4 & \\
\hline Transport & 12 & 1.7 & 12 & 1.8 & \\
\hline Others & 24 & 3.4 & 33 & 4.8 & \\
\hline \multicolumn{6}{|l|}{ Stage } \\
\hline I & 421 & 60.2 & & & \\
\hline II & 214 & 30.6 & & & \\
\hline III & 64 & 9.2 & & & \\
\hline
\end{tabular}

Abbreviation: SD, standard deviation. frequencies differ significantly between cases and control subjects $(P=0.009)$. When the GG genotype was used as reference, multivariate logistic regression analysis indicated that the homozygous $\mathrm{CC}$ carriers had a statistically significantly decreased effect of CWP $(P=0.019$, adjusted $\mathrm{OR}=0.47,95 \% \mathrm{CI}=0.24-0.91)$, but the heterozygous GC carriers had no statistical difference in risk of CWP $(P=0.108$, adjusted $\mathrm{OR}=1.21,95 \% \mathrm{CI}=0.96-1.53)$.

\section{Association and stratification analysis between MIF polymorphism and CWP risk}

Next, because the presentation of two $\mathrm{C}$ alleles causes the protective effect of CWP, we use the recessive model to illustrate the association between MIF polymorphism and CWP risk in the association and stratification analysis (Table 3). The recessive model revealed that the $\mathrm{CC}$ carriers had a statistically significantly decreased effect of CWP $(P=0.015$, adjusted $\mathrm{OR}=0.44,95 \% \mathrm{CI}=0.22-0.85)$, compared with the combined $\mathrm{GG} / \mathrm{GC}$ genotype. In the stratification analysis, we found that the risk decrease of the $\mathrm{CC}$ carriers was more pronounced among the subgroup of smokers $(P=0.016$, adjusted $\mathrm{OR}=0.31,95 \% \mathrm{CI}=0.12-0.81$ ).

\section{Discussion}

In this present study, we investigated the associations between the $M I F-173 \mathrm{G} / \mathrm{C}$ polymorphism and the risk of CWP in a Chinese population. As the two $\mathrm{C}$ alleles play the protective part in CWP and the GC genotype had no significant difference with CWP, we selected the recessive model to observe the association between the MIF polymorphism and CWP risk. Then, we found that when the combined GG/GC genotype was used as reference, the homozygous $\mathrm{CC}$ carriers had a statistically significantly decreased effect of CWP, which was more evident among smokers.

Although the pathophysiology has not been fully understood, CWP and silicosis involve complex interactions among multiple genes and dust exposure. Some evidence has suggested that the alveolar macrophages play a prominent role in lung inflammation and fibrosis via the production of a large panel of mediators including cytokines, reactive oxygen species, enzymes, and arachidonic acid metabolites. ${ }^{25,26}$ Polymorphisms in cytokine genes have been reported to contribute to the recognized stable interindividual variation in the level of cytokine production rates. ${ }^{26-28}$ Cytokines play a critical role in the prevalence of inflammatory diseases that relate to the functional T-cell 
Table 2 Distributions of genotypes of MIF - I73G/C associations with risk of coal workers' pneumoconiosis (CWP)

\begin{tabular}{|c|c|c|c|c|c|c|c|}
\hline \multirow{2}{*}{$\begin{array}{l}\text { Variables } \\
\text { (Genotypes) }\end{array}$} & \multicolumn{2}{|c|}{ CWP cases $(n=699)$} & \multicolumn{2}{|c|}{ Controls $(n=677)$} & \multirow[t]{2}{*}{$P^{a}$} & \multirow[t]{2}{*}{ OR $(95 \% \mathrm{Cl})$} & \multirow[t]{2}{*}{ OR $(95 \% \mathrm{Cl})^{\mathrm{a}}$} \\
\hline & $\mathbf{N}$ & $\%$ & $\mathbf{N}$ & $\%$ & & & \\
\hline GG & 448 & 64.1 & 450 & 66.5 & 0.009 & 1.00 & 1.00 \\
\hline GC & 238 & 34.0 & 198 & 29.2 & & $1.21(0.96-1.52)$ & $1.21(0.96-1.53)$ \\
\hline $\mathrm{CC}$ & 13 & 1.9 & 29 & 4.3 & 0.019 & $0.45(0.23-0.88)$ & $0.47(0.24-0.91)$ \\
\hline
\end{tabular}

Note: aAdjusted for age, exposure years, and pack-years of smoking in logistic regression model.

Abbreviations: $\mathrm{Cl}$, confidence interval; $\mathrm{OR}$, odds ratio.

subsets known as T helper 1 and T helper $2 .{ }^{29}$ As a proinflammatory cytokine released from $\mathrm{T}$ cells and macrophages, MIF plays an important role in inflammatory response..$^{30,31}$ It has been involved in the pathogenesis of immune and inflammatory diseases, including rheumatoid arthritis, pneumonia, ulcerative colitis, pancreatitis, and oligoarticular juvenile idiopathic arthritis. ${ }^{19,20,32-34}$ Thus, the functional variation in $M I F$ may play a role in the etiology of CWP. Although how the $M I F-173 \mathrm{G} / \mathrm{C}$ polymorphism affects the inflammatory reactions remains unclear, some studies have suggested that the polymorphism may influence the protein functions. The $\mathrm{G}$ to $\mathrm{C}$ transition at MIF polymorphism creates a potential transcription factor-binding site for activator protein-4, suggesting that polymorphism could functionally alter $M I F$ production.$^{18}$ Kaznowska et a ${ }^{35}$ reported that the polymorphism of $M I F$ was associated with increased production of MIF and has been found to confer increased risk of susceptibility to chronic inflammatory diseases. Gomez et $\mathrm{al}^{36}$ found that $M I F-173 \mathrm{G} / \mathrm{C}$ polymorphism influenced the risk of developing human tuberculosis in a well-defined Latin-American population. The subjects with the $-173 \mathrm{GC}$ genotype had significantly increased risk, compared with the GG homozygous genotype in tuberculosis. Prencipe et al ${ }^{37}$ indicated that the $M I F$ expression was increased in the lung and serum of preterm infants and suggested that the high-producing $M I F-173 \mathrm{C}$ allele was a protective factor for bronchopulmonary dysplasia from a case-control study of 25 bronchopulmonary dysplasia patients and 66 controls. In the present study, carriers of the CC genotype had a decreased risk of CWP compared with the GG/GC genotypes. One possible explanation is that the $\mathrm{C}$ allele may result in increased anti-inflammatory cytokine production or a profibrogenic factor favoring the fibrotic nodular lesions of the lung. An interesting thing is that there was no CC genotype in stage III, which may suggest that the polymorphism plays a part in the development of CWP rather than the subsequent progression of CWP. It has been posed that different stages of CWP have different etiology involving different genetic defects..$^{38}$

To our knowledge, this is the first study to investigate the role of genetic polymorphism in MIF in the development of CWP. Our present study indicates that the functional $M I F-173 \mathrm{G} / \mathrm{C}$ polymorphism is associated with the increased risk of CWP in the Chinese population. Further validated studies with diverse populations are warranted to confirm our findings.

Table 3 Stratification analyses between the genotypes of MIF - I73G/C and coal workers' pneumoconiosis risk

\begin{tabular}{|c|c|c|c|c|c|c|c|}
\hline \multirow[t]{3}{*}{ Variables } & \multirow[t]{3}{*}{ Cases/controls } & \multicolumn{4}{|c|}{ Genotypes (cases/controls) } & \multirow[t]{3}{*}{$P^{a}$} & \multirow[t]{3}{*}{ OR $(95 \% \mathrm{CI})^{\mathrm{a}}$} \\
\hline & & \multicolumn{2}{|l|}{ GG/GC } & \multicolumn{2}{|l|}{ CC } & & \\
\hline & & $\mathbf{n}$ & $\%$ & $\mathbf{n}$ & $\%$ & & \\
\hline Total & $699 / 677$ & $686 / 648$ & $98.1 / 95.7$ & $13 / 29$ & $1.9 / 4.3$ & 0.015 & $0.44(0.22-0.85)$ \\
\hline \multicolumn{8}{|c|}{ Exposure years } \\
\hline$<27$ & $278 / 260$ & $274 / 249$ & $98.6 / 95.8$ & $4 / 11$ & I.4/4.2 & 0.078 & $0.32(0.10-1.01)$ \\
\hline$\geq 27$ & $421 / 417$ & $412 / 399$ & $97.9 / 95.7$ & $9 / 18$ & $2.1 / 4.3$ & 0.112 & $0.52(0.23-1.17)$ \\
\hline \multicolumn{8}{|c|}{ Smoking status } \\
\hline Never & $345 / 351$ & $338 / 339$ & $98.0 / 96.6$ & $7 / 12$ & $2.0 / 3.4$ & 0.364 & $0.64(0.25-1.67)$ \\
\hline Ever & $354 / 326$ & $348 / 309$ & $98.3 / 94.8$ & $6 / 17$ & $1.7 / 5.2$ & 0.016 & $0.3 \mathrm{I}(0.12-0.8 \mathrm{I})$ \\
\hline \multicolumn{8}{|l|}{ Stage } \\
\hline 1 & $421 / 677$ & $411 / 648$ & $97.6 / 95.7$ & $10 / 29$ & $1.5 / 4.3$ & & \\
\hline II & $214 / 677$ & $211 / 648$ & $98.6 / 95.7$ & $3 / 29$ & $\mathrm{I} .4 / 4.3$ & & \\
\hline III & $64 / 677$ & $64 / 648$ & $100.0 / 95.7$ & $0 / 29$ & $0.0 / 4.3$ & & \\
\hline
\end{tabular}

Note: ${ }^{a}$ Adjusted for age, exposure years, and pack-years of smoking in logistic regression model. Abbreviations: $\mathrm{Cl}$, confidence interval; OR, odds ratio. 


\section{Acknowledgments}

This study was partly supported by the National Natural Science Foundation of China (81072282), and the project was funded by the Priority Academic Program Development of Jiangsu Higher Education Institutions (PAPD). The funders had no role in study design, data collection and analysis, decision to publish, or preparation of the manuscript. No additional external funding was received for this study.

\section{Disclosure}

The authors declare no conflicts of interest in this work.

\section{References}

1. Calandra T, Roger T. Macrophage migration inhibitory factor: a regulator of innate immunity. Nat Rev Immunol. 2003;3(10):791-800.

2. Schober A, Bernhagen J, Weber C. Chemokine-like functions of MIF in atherosclerosis. J Mol Med (Berl). 2008;86(7):761-770.

3. Lue H, Dewor M, Leng L, Bucala R, Bernhagen J. Activation of the JNK signalling pathway by macrophage migration inhibitory factor (MIF) and dependence on CXCR4 and CD74. Cell Signal. 2011 23(1):135-144.

4. Heinrichs D, Knauel M, Offermanns C, et al. Macrophage migration inhibitory factor (MIF) exerts antifibrotic effects in experimental liver fibrosis via CD74. Proc Natl Acad Sci U S A. 2011;1a08(42): 17444-17449.

5. Liu L, Ji C, Chen J, et al. A global genomic view of MIF knockdownmediated cell cycle arrest. Cell Cycle. 2008;7(11):1678-1692.

6. Takahashi A, Iwabuchi K, Suzuki M, Ogasawara K, Nishihira J, Onoe K. Antisense macrophage migration inhibitory factor (MIF) prevents anti-IgM mediated growth arrest and apoptosis of a murine B cell line by regulating cell cycle progression. Microbiol Immunol. 1999;43(1):61-67.

7. Plant BJ, Gallagher CG, Bucala R, et al. Cystic fibrosis, disease severity, and a macrophage migration inhibitory factor polymorphism. Am $J$ Respir Crit Care Med. 2005;172(11):1412-1415.

8. Bargagli E, Olivieri C, Nikiforakis N, et al. Analysis of macrophage migration inhibitory factor (MIF) in patients with idiopathic pulmonary fibrosis. Respir Physiol Neurobiol. 2009;167(3):261-267.

9. Denz A, Pilarsky C, Muth D, Ruckert F, Saeger HD, Grutzmann R. Inhibition of MIF leads to cell cycle arrest and apoptosis in pancreatic cancer cells. J Surg Res. 2010;160(1):29-34.

10. Rimal B, Greenberg AK, Rom WN. Basic pathogenetic mechanisms in silicosis: current understanding. Curr Opin Pulm Med. 2005;11(2) 169-173.

11. Fujimura N. Pathology and pathophysiology of pneumoconiosis. Curr Opin Pulm Med. 2000;6(2):140-144.

12. Fukuda Y, Ishizaki M, Masuda Y, Kimura G, Kawanami O, Masugi Y. The role of intraalveolar fibrosis in the process of pulmonary structural remodeling in patients with diffuse alveolar damage. Am J Pathol. 1987; 126(1):171-182.

13. Danila E, Sileikiene V, Nargela R, Zurauskas E, Loskutoviene G. Different course of silicosis in four brothers of one family. Int J Occup Med Environ Health. 2009;22(1):51-57.

14. Song Z, Qian H, Wang S, Jia X, Ye Y, Ni C. The incidences of CWP in Xuzhou coal mines from 2003 to 2008. Zhonghua Lao Dong Wei Sheng Zhi Ye Bing Za Zhi. 2011;29(1):61-63.

15. Kudrin A, Ray D. Cunning factor: macrophage migration inhibitory factor as a redox-regulated target. Immunol Cell Biol. 2008;86(3): 232-238.

16. Lai KN, Leung JC, Metz CN, Lai FM, Bucala R, Lan HY. Role for macrophage migration inhibitory factor in acute respiratory distress syndrome. J Pathol. 2003;199(4):496-508.
17. De Benedetti F, Meazza C, Vivarelli M, et al. Functional and prognostic relevance of the -173 polymorphism of the macrophage migration inhibitory factor gene in systemic-onset juvenile idiopathic arthritis. Arthritis Rheum. 2003;48(5):1398-1407.

18. Donn R, Alourfi Z, De Benedetti F, et al. Mutation screening of the macrophage migration inhibitory factor gene: positive association of a functional polymorphism of macrophage migration inhibitory factor with juvenile idiopathic arthritis. Arthritis Rheum. 2002;46(9):2402-2409.

19. Vivarelli M, D’Urbano LE, Insalaco A, et al. Macrophage migration inhibitory factor (MIF) and oligoarticular juvenile idiopathic arthritis (o-JIA): association of MIF promoter polymorphisms with response to intra-articular glucocorticoids. Clin Exp Rheumatol. 2007;25(5):775-781.

20. Makhija R, Kingsnorth A, Demaine A. Gene polymorphisms of the macrophage migration inhibitory factor and acute pancreatitis. JOP. 2007;8(3):289-295.

21. Nohara H, Okayama N, Inoue N, et al. Association of the $-173 \mathrm{G} / \mathrm{C}$ polymorphism of the macrophage migration inhibitory factor gene with ulcerative colitis. J Gastroenterol. 2004;39(3):242-246.

22. Plant BJ, Ghani S, O'Mahony MJ, et al. Sarcoidosis and MIF gene polymorphism: a case-control study in an Irish population. Eur Respir J. 2007;29(2):325-329.

23. Wang M, Ye Y, Qian H, et al. Common genetic variants in pre-microRNAs are associated with risk of coal workers' pneumoconiosis. J Hum Genet. 2010;55(1):13-17.

24. Wang M, Wang S, Song Z, et al. Associations of IL-4, IL-4R, and IL-13 gene polymorphisms in coal workers' pneumoconiosis in China: a case-control study. PLoS One. 2011;6(8):e22624.

25. Castranova V, Vallyathan V. Silicosis and coal workers' pneumoconiosis. Environ Health Perspect. 2000;108 Suppl 4:675-684.

26. Yucesoy B, Vallyathan V, Landsittel DP, Simeonova P, Luster MI. Cytokine polymorphisms in silicosis and other pneumoconioses. Mol Cell Biochem. 2002;234-235(1-2):219-224.

27. Zhai R, Liu G, Ge X, et al. Genetic polymorphisms of MnSOD, GSTM1, GSTT1, and OGG1 in coal workers' pneumoconiosis. J Occup Environ Med. 2002;44(4):372-377.

28. Yao W, Wang ZM, Wang MZ, Hao CF, Wang N. The relationship between the concentration of TGF-beta1 in serum and its gene polymorphisms in CWP. Sichuan Da Xue Xue Bao Yi Xue Ban. 2005;36(6):827-829.

29. Yazdanbakhsh M, Kremsner PG, van Ree R. Allergy, parasites, and the hygiene hypothesis. Science. 2002;296(5567):490-494.

30. Sevketoglu E, Yilmaz A, Gedikbasi A, et al. Urinary macrophage migration inhibitory factor in children with urinary tract infection. Pediatr Nephrol. 2009;25(2):299-304.

31. Otukesh H, Fereshtehnejad SM, Hoseini R, et al. Urine macrophage migration inhibitory factor (MIF) in children with urinary tract infection: a possible predictor of acute pyelonephritis. Pediatr Nephrol. 2009;24(1):105-111.

32. Yende S, Angus DC, Kong L, et al. The influence of macrophage migration inhibitory factor gene polymorphisms on outcome from community-acquired pneumonia. Faseb J. 2009;23(8):2403-2411.

33. Shiroeda H, Tahara T, Nakamura M, et al. Association between functional promoter polymorphisms of macrophage migration inhibitory factor (MIF) gene and ulcerative colitis in Japan. Cytokine. 2010;51(2):173-177.

34. Donn RP, Shelley E, Ollier WE, Thomson W. A novel 5'-flanking region polymorphism of macrophage migration inhibitory factor is associated with systemic-onset juvenile idiopathic arthritis. Arthritis Rheum. 2001;44(8):1782-1785.

35. Kaznowska E, Przybylowska K, Kulig A. The $-173 \mathrm{G} / \mathrm{C}$ polymorphism of the promoter region macrophage migration inhibitory factor gene is not associated with incidence of pulmonary hamartoma. Pol J Pathol. 2007;58(3):189-192.

36. Gomez LM, Sanchez E, Ruiz-Narvaez EA, Lopez-Nevot MA, Anaya JM, Martin J. Macrophage migration inhibitory factor gene influences the risk of developing tuberculosis in northwestern Colombian population. Tissue Antigens. 2007;70(1):28-33. 
37. Prencipe G, Auriti C, Inglese R, et al. A polymorphism in the macrophage migration inhibitory factor promoter is associated with bronchopulmonary dysplasia. Pediatr Res. 2011;69(2):142-147.
38. Chang KC, Leung CC, Tam CM. Tuberculosis risk factors in a silicotic cohort in Hong Kong. Int J Tuberc Lung Dis. 2001;5(2):177-184.

\section{Publish your work in this journal}

The International Journal of Interferon, Cytokine and Mediator Research is an international, peer-reviewed, open-access, online journal. The focus of the journal is to publish original research, reports, editorials, reviews and commentaries on all aspects of interferon, cytokine and mediators of inflammation from labora- tory science to therapeutic indications and clinical studies. The manuscript management system is completely online and includes a very quick and fair peer-review system, which is all easy to use. Visit http://www.dovepress.com/testimonials.php to read real quotes from published authors.

Submit your manuscript here: http://www.dovepress.com/international-journal-of-interferon-cytokine-and-mediator-research-journal 